\title{
GERAÇÃO DE IMAGEM ESFÉRICA EM 360 GRAUS COMO ESTRATÉGIA DE APRENDIZAGEM APLICADA NO ÂMBITO ESCOLAR
}

\section{CREATING SPHERICAL 360-DEGREE IMAGES AS LEARNING STRATEGY IN UNIVERSITY CONTEXT}

\author{
Daniele $\operatorname{Troyan}^{1}$ \\ Maria do Carmo Duarte Freitas, Dra. Eng. ${ }^{2}$ \\ Celso Yoshikazu Ishida, Dr. ${ }^{3}$
}

Relata a experiência do uso da fotografia no Projeto de Extensão "Projeção e Visualização Científica dos 100 anos de Dados Históricos UFPR" como ferramenta capaz de desenvolver o raciocínio espacial e de visualização que, se aplicada a educação, estimula e fixa a atenção do aluno e o conteúdo das disciplinas. Identifica as vantagens e desvantagens de seu uso como prática didático-pedagógica em classe para trabalhar temas de criatividade. $O$ experimento faz uso da tecnologia 360 graus esférico capaz de captar e unir séries de fotos de uma câmera digital amadora (que não permite troca de lentes) por intermédio de programas gratuitos e fornece o modelo de realidade virtual, que permite a real noção de tempo e espaço, sendo possível a visualização do todo, com o giro da imagem, e também a visualização dos detalhes por aproximação. Obtivemos resultados com boa qualidade de imagem e custo mais baixo que o utilizado por empresas. Tem-se a expectativa de unir temas como a educação e a tecnologia em escolas públicas, propiciando aplicações diferenciadas aos estudantes e estimulando o interesse pelos estudos.

Palavras-chave: Tecnologia 360 graus. Softwares gratuitos. Métodos educativos escolares. Novos métodos de ensino. Fotografia.

This article aims to describe experiences of using photography as a tool to develop spatial reasoning and visualization, which stimulates and fixed the attention of the students and the contents of the disciplines. Search still identify advantages and disadvantages of their use as didactic-pedagogic practice in class to work themes of creativity. The experiment makes use of 360-degree spherical technology capable of capturing and combines a serie of photos by no interchangeable-lens digital camera and specific free software and the model provides enhanced virtual reality, allowing real-time notion and space, making it possible to visualize the whole, with the rotation of the image, and also to visualize the details by approximation. As results, it was obtained image quality and low cost if compared with professional services. There is the expectation of

\footnotetext{
${ }^{1}$ Graduanda em Administração - UFPR - troyandaniele@gmail.com

${ }^{2}$ Professora da Universidade Federal do Paraná. Engenheira Civil (Universidade de Fortaleza), Mestre e Doutora em Engenharia da Produção pela Universidade Federal de Santa Catarina. mcf@ufpr.br

${ }^{3}$ Professor da Universidade Federal do Paraná. Bacharelado em Informática, Mestrado em Informática e Doutorado em Métodos Numéricos em Engenharia, pela UFPR, e Doutorado Sandwich em Matemática Aplicada - Université Paris-Sud XI. celsoishida@ufpr.br
} 
uniting themes like education and technology in public schools, allowing different applications to students and stimulating interest in studies.

Keywords: Technology 360 degrees. Free software. School educational methods. New teaching methods. Photograph.

\section{INTRODUÇÃO}

A educação nas escolas feita de maneira tradicional desde seu surgimento teve transformações com o advento da tecnologia, como a utilização de computadores, lousas digitais e da fotografia. Em tempos onde novas tecnologias surgem e rapidamente ficam obsoletas, torna-se importante a existência de opções para a modernização dos métodos educativos escolares. Em sala de aula o campo visual é importante, pois retém a atenção dos alunos e fixa melhor o conteúdo despertando a sua imaginação.

O surgimento da fotografia no século XVIII trouxe consigo a possibilidade de resgatar momentos de alegria, tristeza, fatos e dados da história das pessoas, famílias e cidades. A evolução da tecnologia e das máquinas e sua consequente redução de custos de aquisição, aliada à facilidade existente com o advento da fotografia digital abre um mundo novo para sua aplicação, além de favorecer o uso em outros contextos.

Gomes (2003) pesquisou a história da educação nas imagens fotográficas e outras fontes complementares, discutiu a possibilidade de uso de meios alternativos na educação histórica, como fotografias, revistas e jornais, considerando a visão de conjunto da obra aprofundada e não apenas como dados. O autor considera a fotografia testemunho válido, e afirma que sozinha ela não permite fazer inferências de caráter histórico e deve, portanto estar associada a outros meios, como dados orais e bibliográficos, mapas e documentos. A fotografia como ferramenta de educação pode ser aplicada em disciplinas e ambientes diferentes, sendo majoritariamente caracterizado como trabalho prático, pois é necessário o envolvimento individual-coletivo para 0 êxito.

Lanz citada por Fernandes (2005) ilustra que para o estudo com imagens realmente atingir a criança de forma positiva deve ser dado não de forma abstrata e teórica, mas sim a partir de fenômenos, de imagens que utilizem o manancial de forças de sentimentos e fantasias presentes na 
criança. Além de estimular a observação, vendo sutilezas e detalhes, reeducar o olhar pode estimular o uso da fotografia na educação.

Este artigo tem por objetivo relatar experiências do uso da fotografia como ferramenta capaz de desenvolver raciocínio espacial e de visualização, estimulando e fixando a atenção dos alunos e os conteúdos das disciplinas. A proposta surgiu durante as discussões de aplicação da fotografia nos experimentos do Projeto de Extensão UFPR 100 anos. Busca-se ainda identificar vantagens e desvantagens de seu uso como prática didáticopedagógica em classe para trabalhar temas de criatividade e aprimorar 0 conhecimento.

\section{Recurso fotográfico aplicado à educação}

No uso do recurso fotográfico aplicado a educação, Fernandes (2005) aponta que a fotografia é mediadora subversiva na produção do conhecimento e para provar isso aplicou os recursos dela em aulas de biologia para mostrar mais a fundo os seres vivos aos alunos, bem como despertar a curiosidade, em aspectos como: O que comem? Onde vivem? Como se locomovem? Fazendo a ilustração desses processos com o recurso da fotografia. Para tanto utilizou de slides, (também conhecido por transparência ou dispositivo, trata-se de imagem estática, positiva, geralmente em cores criadas sobre uma base transparente utilizando de meios fotoquímicos e montados em moldura que possibilita sua projeção numa tela), percebeu-se nos alunos certa admiração e também estranheza que até então não tinham acesso a essa tecnologia. Os resultados alcançados por Fernandes culminaram na motivação e disseminação do conhecimento aos alunos no que tange a área de biologia (fungos, cobras, morfologia, sistemas digestivo, paisagens). Com resgate da fotografia foi possível obter maiores detalhes e permitir melhor visualização e discussão do conteúdo para promover atividades e dinâmica de grupo, questionários, além de agrupamentos descritivos a partir de imagens.

Silveira e Alves (2008) investigaram a contribuição da fotografia na formação de sujeitos atuantes e participativos no processo socioambiental. Para elas a fotografia é a forma elaborada e inteligível de ter acesso ao conhecimento. Propõe para tanto o uso de oficinas e dinâmicas de grupo, despertando a prática consciente no que envolve a educação ambiental, e 
relata as mudanças ocorridas na humanidade desde o advento da máquina fotográfica, que possibilitou a unicidade do processo fotográfico, onde a cena produzida jamais pode se reproduzir existencialmente. Enfatizaram-se os diversos pontos de vista desenvolvendo nas pessoas a noção de pertencimento ao grupo e a noção de mundo, objetivando a prática do pensar global e agir local a fim de transformar a sociedade para melhor! E, assim, propondo sair da inércia existente nos meios regulares de educação e aceitar inovar.

Em acordo Faria e Germano (2003) demonstraram a utilização de recursos multimídia no projeto ACAED, sistema de e-Learning do Instituto Tecnológico de Aeronáutica (ITA) para a captação visual dos experimentos e dos idealizadores da Feira de Ciências do ITA. Na época, os autores verificaram a crescente facilidade de acesso dos estudantes aos computadores que eram vendidos como kit multimídia, possibilitando a captação e envio de áudio, vídeo e fotos digitais. E, reconhecendo a escassez de recursos da rede escolar pública frente aos países desenvolvidos, o projeto reforçou a utilização dos equipamentos disponíveis: uma câmera fotográfica com visor LCD e um computador sem programas especiais de edição de imagens e vídeos. Mesmo com poucos recursos, os autores realizaram o projeto para duzentos e quarenta (240) alunos da primeira e segunda série; e, assim, divulgando com sucesso o conteúdo da feira com as imagens e vídeos.

\section{Fotografia - conceito e história}

A definição do conceito de fotografia é a criação de imagens por exposição luminosa, fixando em superfície sensível, consiste em conservar o momento em imagem segundo Busnardo e Araujo (2010). A fotografia é a memória e com ela se confunde, por ser fonte inesgotável de emoção e informação Bernardo (2007). Memória da vida social e pessoal, do mundo físico e natural. Registro que enquanto dura, cristaliza a imagem escolhida e refletida. Também é a paralisação do relógio que flui ininterruptamente, pois retrata o instante da vida. Dá-nos a real noção de tempo e espaço, fazendo com que reconstituamos em nossa mente os fatos vividos, as paisagens observadas, os momentos por quais passamos. 
Câmara ou câmera fotográfica deriva-se de câmara escura, uma caixa preta com orifício para entrar luz, e com uma superfície fotossensível, como sensor digital ou filme fotográfico Salles (2008). A luz viaja em linha reta, portanto atravessa a lente da câmera e projeta-se sobre a superfície fotossensível formando uma imagem invertida do que fotografamos (figura 1). Os princípios norteadores da câmara escura, cuja autoria é de Aristóteles, sempre estiveram presentes nas câmeras fotográficas (sejam as que utilizam filme ou as digitais).

\section{FIGURA 1 - FORMAÇÃO DA IMAGEM NO INTERIOR DA CÂMERA}

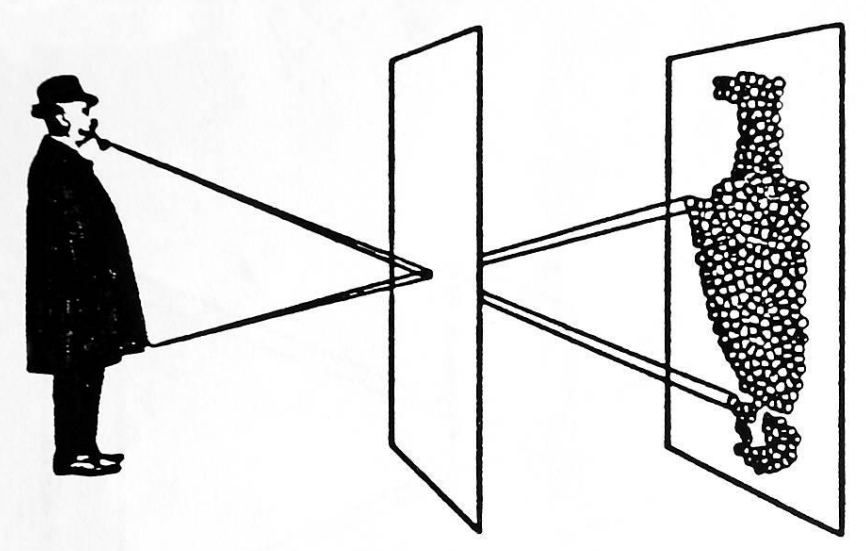

FONTE: Oka e Roperto (2002)

A câmara escura já existia há quatro (4) séculos, mas foi no ano de 1822 que Joseph Nicéphore Niépce conseguiu fixar uma imagem sobre peça metálica, o que representa um importante fato na história. Porém, a primeira imagem reconhecida como fotografia atribui-se ao francês Niépce em 1826 (figura 2 e Quadro 1), ela exigiu cerca de oito (8) horas de exposição solar, numa placa de estanho coberto com derivado de petróleo fotossensível chamado "Betume da Judéia", o que ele chamou de "heliografia" gravura com a luz do sol.

QUADRO 1: RELATA ANO, AUTOR E A PRIMEIRA FOTOGRAFIA DO TIPO TIRADA

\begin{tabular}{|c|l|l|}
\hline ANo & Primeira fotografia & \multicolumn{1}{c|}{ AUTOR } \\
\hline 1826 & Preto e branco & Joseph Nicéphore Niépce \\
\hline 1861 & Colorida & James Clerk Maxwell \\
\hline 1990 & Digital & Empresa Kodak \\
\hline
\end{tabular}

FONTE: Autora, 2012 
FIGURA 2: PRIMEIRA FOTOGRAFIA DO MUNDO, DE 1826, OBTIDA POR NIÉPCE.

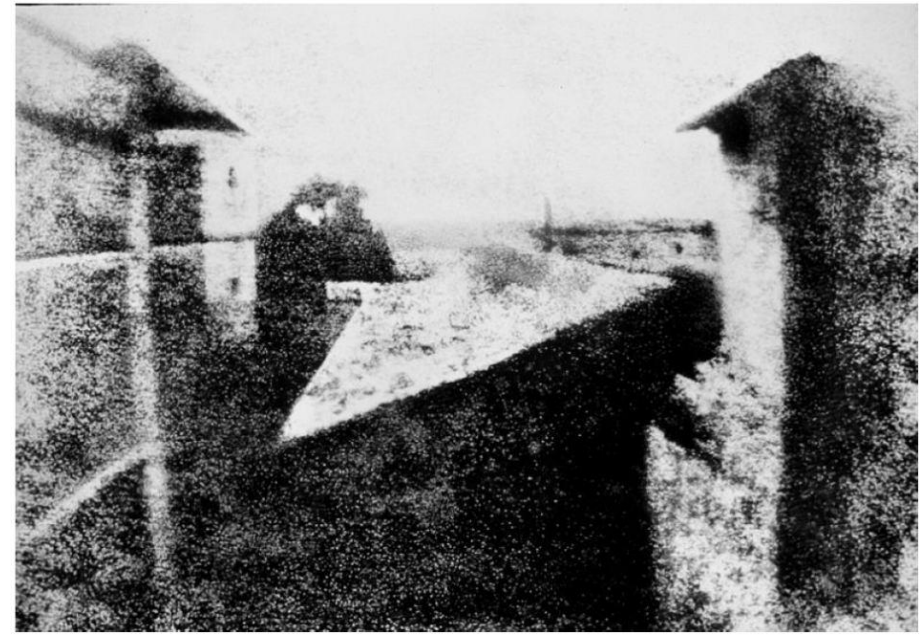

FONTE: Resende, H. 2007.

FIGURA 3: O FOTOGRAFO FRANCÊS JOSEPH-NICÉPHORE NIEPCE

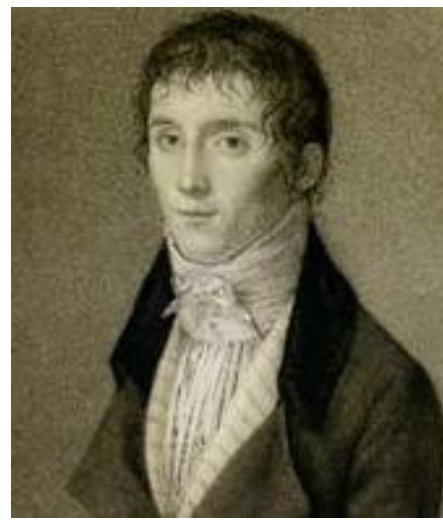

FONTE: Resende, H. 2007.

Relatado por Bernardo (2007) as primeiras exposições de fotografia, a população da época temia que as mesmas substituíssem a pintura, pelo grau de realismo que representa. Logo a fotografia passou a igualmente ser considerada como forma de expressão artística e utilizada na resolução de problemas de ordem científica e técnica (Como ilustra a figura 4). Posteriormente em áreas variadas dentre elas: topografia, auxiliando o levantamento geográfico de várias regiões; estudo dos movimentos humanos e de animais; como registro e identificação de presos pela polícia. Após a descoberta de que as chapas fotográficas podiam ser impressionadas se expostas a determinadas radiações invisíveis, depois nomeadas raios $\mathrm{X}$, 
produziu-se placas e papéis destinados a radiografia que foram utilizados na área médica.

\section{FIGURA 4 - PROJEÇÃO DE DESPACHOS MISCROCÓPICOS DURANTE O CERCO DE PARIS}

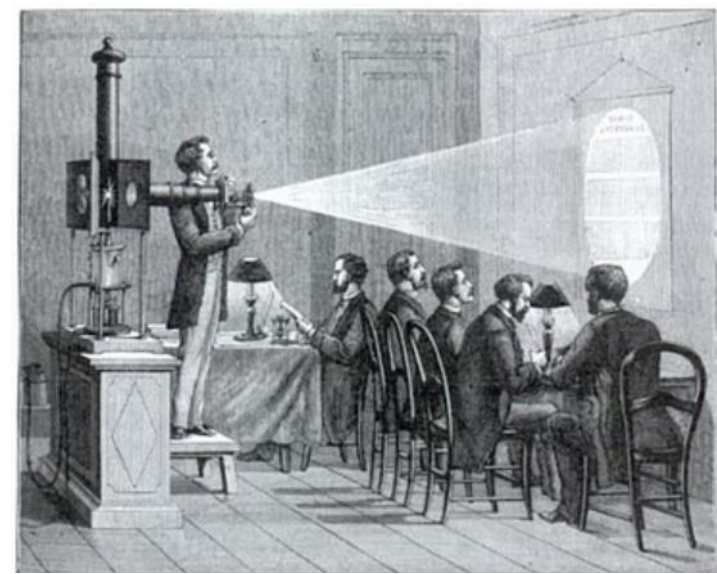

FONTE: História da Luz e das Cores - Bernardo 2007

Bernardo (2007) reforça que a fotografia, além de representar o momento do passado, informa sobre o mundo e a vida. As imagens fornecem série de dados que não são mencionados na história em linguagem escrita, contudo omissões e acréscimos intencionais são possíveis. O gesto, momento ou paisagem ficam congelados na fotografia, despertando a memória a relembrar o passado. O momento vivido, congelado na fotografia é irreversível, e a cena registrada na imagem jamais se repetirá. Contudo a vida segue, onde pessoas retratadas envelhecem, morrem; os cenários se modificam, transfiguram, desaparecem; e as crianças retratadas mantêm-se centenárias. Os registros resistem aos tempos, e são vistos por olhos e lugares desconhecidos. 
FIGURA 5- APARELHOS PARA INCENDIAR AS PÓLVORAS DE MAGNÉSIO (ESQUERDA - PROFISSIONAL; DIREITA - AMADOR, FEITO COM UM CACHIMBO).

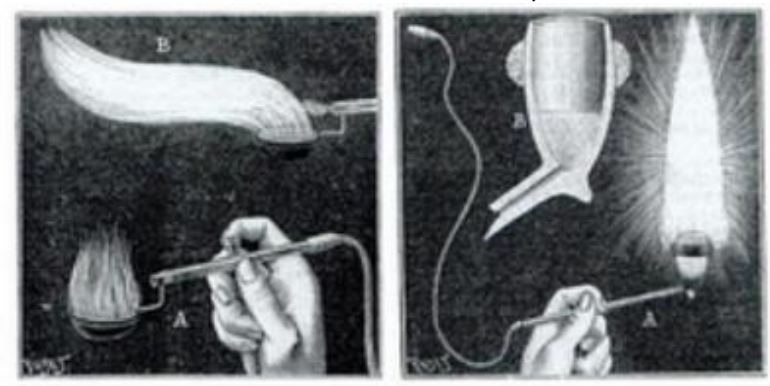

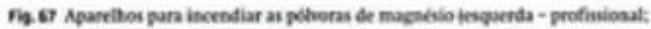

dirvita - amulor, frite con um cachimbot.

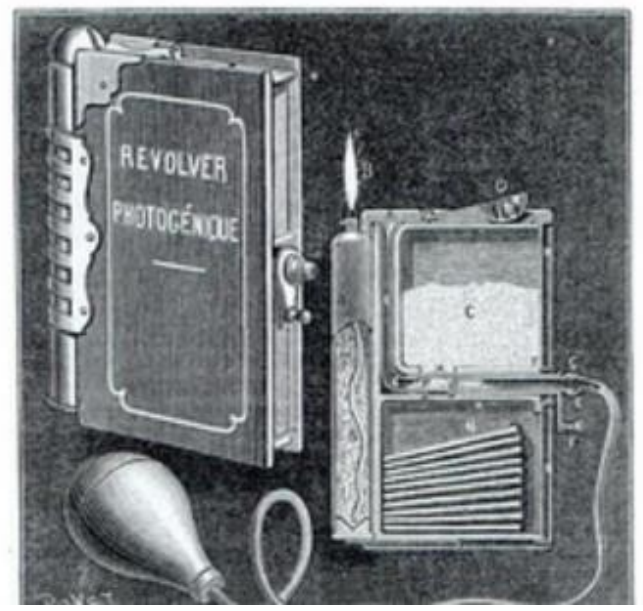

FONTE: História da Luz e das Cores - Bernardo 2007

Bernardo (2007) relata que a experiência de vida, bagagem cultural e sensibilidade inferem diretamente no que o observador irá alcançar e interpretar através da fotografia. A câmera tem acompanhado o homem nos últimos cento e noventa (190) anos, comprovando suas conquistas e trajetórias, desde as primeiras viagens espaciais, utilizada também como forma de documentação familiar, informação e divulgação de fatos, expressão artística e pesquisa cientifica, comprovando que a fotografia é parte indissociável da experiência humana. 
FIGURA 6- UM STAND DA EXPOSIÇÃO FOTOGRÁFICA REALIZADA EM 1886, NO PALÁCIO DE CRISTAL, NO PORTO.

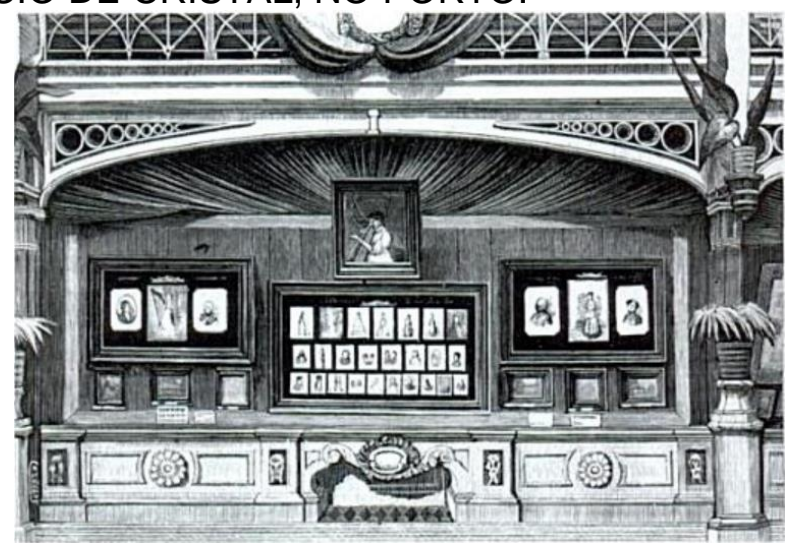

FONTE: História da Luz e das Cores - Bernardo 2007

A fotografia não é obra de um só autor, pois várias pessoas contribuíram para o avanço desta, desde as primeiras tentativas, passando pelas câmeras com filme fotográfico até as digitais. A fotografia digital é mais acessível a todos sem depender de fotógrafo profissional, com facilidade de armazenamento e transmissão, rapidez e agilidade no processo, e que a cada ano tem maior qualidade e menor preço dos equipamentos Bueno (2010).

FIGURA 7 - MÁQUINA FOTOGRÁFICA COM TRIPÉ PARA VIAGEM E KIT PARA VIAGEM

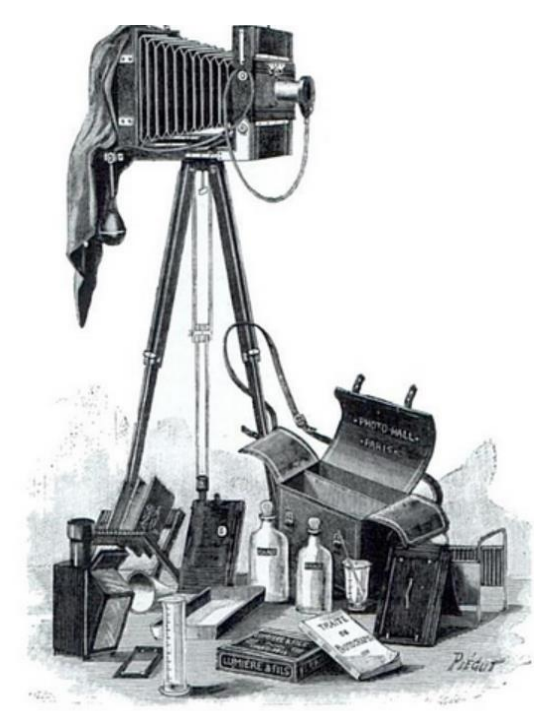

FONTE: História da Luz e das Cores - Bernardo 2007

A junção da telefonia móvel e internet com a fotografia digital passou a fazer parte do cotidiano das pessoas. É possível criar álbuns on-line para diversos propósitos, onde ficam organizadas em pastas e separadas por 
assuntos a critério do usuário, por exemplos: portfólio para divulgar o trabalho de fotógrafos e modelos; negócios para vender seus trabalhos fotográficos realizados.

\section{Uso e aplicação da fotografia}

A fotografia 360 graus esférica possibilita a visão de todos os ângulos (vertical e horizontal) a partir de determinado ponto; com a visão do todo se cria a percepção de como se estivesse no local fotografado. Este tipo de fotografia vem sendo utilizada por empresas como, por exemplo, imobiliárias que demonstram os espaços dos imóveis que estão sendo vendidos. Com isso, os seus clientes podem conhecer diversas opções antes da compra; Como a visão e a sensação de espaço com as fotos em 360 graus esféricas são melhores do que apenas fotos tradicionais (fotos tiradas de câmeras digitais amadoras com representação em duas dimensões), e os clientes acabam otimizando o seu tempo pela necessidade de um menor número de visitas aos imóveis. Este serviço é especializado e requer que os profissionais tenham câmeras com lentes específicas de olho de peixe (fisheye) e softwares estrangeiros pagos.

Assim como outras tecnologias, a fotografia deve ser corretamente utilizada quando utilizada para a educação. Para fazer uso de tecnologias com êxito é necessário ter estratégias e conteúdo. Em estudos que os educadores se limitaram a contar o número de computadores por aluno os resultados não foram satisfatórios, como por exemplo: o governo da Colômbia que distribuiu máquinas a dois mil estudantes, as notas ficaram próximas de zero ou pioraram segundo dados do Banco Mundial, Guimarães e Sorg (2011). Outro caso é verificado em estudo do Ministério da educação no Brasil em 2007, onde alunos que estudaram três (3) anos com materiais digitais estavam atrasados em média seis (6) meses (Guimarães e Sorg 2011). Nesses casos apontados não foi avaliada a utilização das máquinas para passar algum conteúdo, nem a disponibilização e aplicação de cursos além de planilhas e processadores de texto.

Nos países desenvolvidos, a questão do acesso às máquinas já foi superada, por serem adiantados na implantação da tecnologia, e hoje a discussão é sobre como usar a tecnologia da melhor forma, Guimarães e Sorg 
(2011). No quadro 2, estão resumidos os pontos positivos de cada país no uso da tecnologia na educação.

QUADRO 2: PAÍSES DESENVOLVIDOS E SUA RESPECTIVA MELHORIA EM EDUCAÇÃO E TECNOLOGIA.

\begin{tabular}{|l|l|}
\hline País & \multicolumn{1}{|c|}{ Pontos positivos } \\
\hline $\begin{array}{l}\text { Estados } \\
\text { Unidos }\end{array}$ & $97 \%$ da rede pública dispõem de um computador por aluno \\
\hline Alemanha & Mais de 30 mil escolas estão equipadas desde 2011 \\
\hline Inglaterra & $\begin{array}{l}\text { Criou um departamento só para pesquisar e avaliar o uso da } \\
\text { tecnologia em sala de aula }\end{array}$ \\
\hline $\begin{array}{l}\text { Coréia do } \\
\text { Sul }\end{array}$ & Conteúdo curricular fortemente relacionado à tecnologia \\
\hline
\end{tabular}

FONTE: Camila Guimarães e Letícia Sorg (2011)

No Brasil, podemos afirmar que algumas iniciativas têm obtidos bons resultados como mostra o Quadro 3.

QUADRO 3 - RELATA EXPERIÊNCIAS DE TECNOLOGIA UTILIZADAS EM PROL DA EDUCAÇÃO.

\begin{tabular}{|c|c|c|c|c|}
\hline Estudos & Aplicação & Tecnologias & Resultados obtidos & $\begin{array}{l}\text { Local de } \\
\text { Estudo }\end{array}$ \\
\hline $\begin{array}{l}\text { Fundação } \\
\text { Carlos } \\
\text { Chagas }\end{array}$ & $\begin{array}{l}\text { Escolas } \\
\text { públicas - } \\
\text { matemáti- } \\
\text { ca }\end{array}$ & $\begin{array}{l}\text { Lousas digitais, } \\
\text { softwares educativos, } \\
\text { e laptops individuais. }\end{array}$ & $\begin{array}{l}\text { A média em } \\
\text { matemática melhorou } \\
\text { em } 8,3 \text { pontos, contra } \\
0,2 \text { pontos dos que não } \\
\text { usaram tecnologia. }\end{array}$ & $\begin{array}{r}\text { José de } \\
\text { Freitas/PI }\end{array}$ \\
\hline UNESCO & $\begin{array}{l}\text { Escolas } \\
\text { públicas }\end{array}$ & $\begin{array}{l}\text { Lousa digital, e um } \\
\text { computador por } \\
\text { aluno. }\end{array}$ & $\begin{array}{l}\text { Avanço de duas a sete } \\
\text { vezes em relação aos } \\
\text { colegas em sala de } \\
\text { aula comuns }\end{array}$ & $\begin{array}{l}\text { Hortolân- } \\
\text { dia/SP }\end{array}$ \\
\hline $\begin{array}{l}\text { Graded } \\
\text { School }\end{array}$ & $\begin{array}{l}\text { Biologia- } \\
\text { fotossínte- } \\
\text { se }\end{array}$ & $\begin{array}{l}\text { Laptop, Google Docs. } \\
\text { (serviço gratuito de } \\
\text { arquivos on-line), } \\
\text { sites especializados. }\end{array}$ & $\begin{array}{l}\text { Diferenciação no } \\
\text { método de ensino } \\
\text { através de pesquisa } \\
\text { em banco de dados } \\
\text { internacionais, } \\
\text { simulações gráficas e } \\
\text { relatórios. }\end{array}$ & São Paulo \\
\hline $\begin{array}{l}\text { Positivo } \\
\text { Informáti- } \\
\text { ca }\end{array}$ & $\begin{array}{l}\text { Escolas } \\
\text { municipais } \\
- \\
\text { português } \\
\text { e } \\
\text { matemáti- } \\
\text { ca }\end{array}$ & $\begin{array}{l}\text { Softwares educativos, } \\
\text { onde o aluno faz } \\
\text { atividades interativas } \\
\text { e evolui para as mais } \\
\text { difíceis, de acordo } \\
\text { com seu ritmo de } \\
\text { aprendizado. }\end{array}$ & $\begin{array}{l}\text { Integração entre a } \\
\text { tecnologia e o } \\
\text { conteúdo das aulas }\end{array}$ & $\begin{array}{r}\text { Matinhos/ } \\
\text { PR }\end{array}$ \\
\hline
\end{tabular}

FONTE: Revista Época (2011) 
Para que as estatísticas de aprendizado continuem melhorando significativamente, a tecnologia tem que ser usada com sabedoria, não bastando o aluno ter acesso para que as coisas melhorem, como afirma o estrategista educacional da Dell, Mark Weston: "essa era a ideia há trinta (30) anos, agora sabemos que também são necessárias boas práticas de ensino". Como não existe relato anterior da utilização de fotos $360^{\circ}$ esféricas, acreditase que a sua utilização deva estar dentro das boas práticas que estão sendo utilizadas com sucesso.

\section{Materiais e Métodos}

O relato a seguir descreve o experimento realizado em laboratório, visando explorar os recursos disponíveis na tecnologia de fotografia 360 graus esféricas para uso e aplicação dos recursos fotográficos no Projeto de Extensão "Projeção e Visualização Científica dos 100 anos de Dados Históricos UFPR". Fato que despertou para a possibilidade de uso do recurso como uma estratégia didática pedagógica. $E$, com a falta de recursos financeiros para 0 projeto, semelhante a diversas escolhas públicas que possuem os recursos limitados, foi preciso a busca por soluções gratuitas. Foi possível criar fotos 306 com uma câmera digital amadora (que não permite troca de lente) e softwares gratuitos com resultados próximos aos obtidos pelas empresas.

O passo a passo de duas etapas (técnica e prática) é detalhado a seguir para a construção de fotos 360 graus esféricas.

Etapa técnica consiste na instalação de três (3) programas gratuitos encontrados na internet para obter fotografias em 360 graus esféricas. 0 primeiro é o Silverlight, programa da Microsoft compatível com as versões para os sistemas Microsoft Windows e MaC OSX. Este software é última geração para navegadores e plug-ins, e é de fácil instalação.

Os outros dois softwares: Photosynth app e Image Composite Editor (ICE) são utilizados em conjunto com o sítio Photosynth, http://photosynth.net/. As fotos podem ser combinadas pelo programa ICE e enviadas para o sítio através do Photosynth app. O sítio indica o link e instruções para a instalação dos programas em http://photosynth.net/about.aspx. Depois de instalados, execute o programa ICE; acesse o menu "File" e escolha a opção "New Panorama". Selecione todas as fotos e aperte "Open”. Espere alguns minutos 
para que as fotos sejam automaticamente combinadas, quanto maior o número de fotos maior a espera e melhor o resultado. Note que o resultado é uma foto que parece distorcida por estar sendo visualizada em apenas duas dimensões. Observaram-se, também, algumas informações no rodapé do programa como, por exemplo, "Spans $360.0^{\circ}$ horizontally, $180.0^{\circ}$ vertically"; se os números forem iguais a $360^{\circ}$ e $180^{\circ}$ já indicam que a foto resultado terá todos os ângulos. Contudo, se existem espaços vazios (pretos) indica que o programa não conseguiu identificar estas regiões. Se os espaços vazios aparecerem ou se alguma parte da imagem não estiver combinada corretamente, tire novas fotos para preencher os espaços ou corrigir o problema e crie novamente a foto voltando ao passo "New Panorama".

Se a foto resultado for satisfatório é preciso enviar a mesma para o sítio Photosynth. Aperte o botão "Publish to Web" no programa ICE que, automaticamente, executa o programa Photosynth app para o envio. Para continuar o processo de envio é necessário uma conta para acesso ao sítio Photosynth.

Para criar uma conta de inscrição é preciso acessar uma única vez o sítio Photosynth e acessar o link "New Account" e depois "Sign up". Criada a conta, com a senha é possível continuar a execução do programa Photosynth app e executar o upload das imagens combinada. Espere que a foto final seja enviada e acesse o botão "View" que te direciona automaticamente para o sítio com a imagem, onde é possível visualizar e navegar sobre a montagem combinada. A imagem 360 graus esférica fica gravada e associada à sua conta, salvo no sítio do Photosynt, e outras pessoas têm acesso a rápida visualização e interação, por exemplo: http://photosynth.net/view.aspx?cid=12bb8ab9-7049-48b0-a3ec-b367adf4b345. O mesmo exemplo pode ser acessado no site do projeto (http://www.gpcit.ufpr.br/100anos/).

A segunda etapa é prática e destina-se a orientar como usar a máquina digital e as ações necessárias para aproveitar melhor o recurso. Trata-se de tecnologia específica e recente, tendo como foco ressaltar seu uso como recurso didático na educação. Sua utilização visa despertar estímulos crescentes à educação de crianças e jovens com as novidades tecnológicas, desenvolvendo o interesse pelos estudos, despertando a criatividade, saindo 
dos métodos tradicionais, particularmente nas escolas públicas onde há escassez de recursos para diversificar o aprendizado.

Para originar as fotografias 360 graus esféricas, deve-se fazer a captação do material fotográfico. Aconselha-se que as fotos tenham, no mínimo, três (3) megapixels; quanto maior a resolução melhor o resultado. 0 Quadro 4 orienta como tirar as fotos. Observação: O passo 1 pode ser melhorado com a utilização de um tripé.

QUADRO 4 - PROCEDIMENTOS PARA FOTOGRAFIA EM 360 GRAUS

\begin{tabular}{|c|c|}
\hline Passo & Procedimento \\
\hline \multirow[t]{3}{*}{$\begin{array}{l}\text { 1. Posicionamento } \\
\text { corporal }\end{array}$} & $\begin{array}{l}\text { Marcar um ponto no chão para girar em torno dos pés } \\
\text { mantendo o corpo estável }\end{array}$ \\
\hline & $\begin{array}{l}\text { Fixar os cotovelos junto ao corpo e não deixá-los abertos aos } \\
\text { lados }\end{array}$ \\
\hline & Manter os braços alinhados com os dedos dos pés \\
\hline \multirow[t]{2}{*}{$\begin{array}{l}\text { 2.Preparação para } \\
\text { Fotografia }\end{array}$} & $\begin{array}{l}\text { Identificar "marcadores" em linha vertical e dependendo do } \\
\text { local, por exemplo, podem ser detalhes na parede }\end{array}$ \\
\hline & $\begin{array}{l}\text { Ter uma linha imaginária divisória para estabelecer o mesmo } \\
\text { formato para cada foto }\end{array}$ \\
\hline \multirow[t]{6}{*}{ 3. Fotografar } & $\begin{array}{l}\text { Tirar uma foto e rotacionar horizontalmente ou verticalmente } \\
\text { (pode-se, por exemplo, tirar fotos rotacionando } \\
\text { horizontalmente até cobrir } 360 \text { graus e depois aumentar ou } \\
\text { diminuir o ângulo na vertical para tirar mais um conjunto de } \\
\text { fotos que cubra } 360 \text { graus na horizontal) }\end{array}$ \\
\hline & Cobrir cada "marcador" do passo 2 com três fotos diferentes \\
\hline & $\begin{array}{l}\text { Tirar fotos verticalmente ou horizontalmente, não misturando } \\
\text { os modos. }\end{array}$ \\
\hline & $\begin{array}{l}\text { Estabelecer diferença entre as fotos com ângulo de } 35 \text { graus } \\
\text { para cima e } 15 \text { graus na horizontal, observando todos os } \\
\text { detalhes }\end{array}$ \\
\hline & $\begin{array}{l}\text { Fotografar sempre com a mesma orientação de aproximação } \\
\text { (não utilize o zoom) }\end{array}$ \\
\hline & $\begin{array}{l}\text { Não economizar no número de fotos, quanto mais } \\
\text { sobreposição melhor }\end{array}$ \\
\hline
\end{tabular}

FONTE: Autora, 2012.

Uma dica que pode ajudar: o segredo da fotografia é luz, ou seja, quanto mais luz melhor e, como as fotos serão combinadas, é preciso que todas tenham a mesma exposição de luz. Logo, evite tirar fotos no início da manhã e no final da tarde quando existe a variação da iluminação. Aconselha-se, também, que não se utilize o flash; iluminação natural é preferível. A seguir um exemplo prático para ilustrar como é possível executar o trabalho. 


\section{Aplicação da Fotografia 360 graus: Pátio da UFPR}

Fotografou-se 0 ambiente interno do prédio de Ciências Sociais Aplicadas da UFPR com o auxílio de um tripé e uma máquina fotográfica digital comum (Sony Cyber-shot W170, 10 Megapixels, modelo que atualmente já foi substituído por outros novos modelos). A metodologia consistiu em iniciar fotografando o chão e rodapé da parede, depois a parede toda, posteriormente a parte superior da parede e parte do teto, e finalmente a parte superior do teto; assim sucessivamente em círculo até fotografar todo ambiente, sempre posicionando a câmera de modo à sobre posicionar a imagem anterior, inclusive em cada etapa vertical (quatro conjuntos nesse caso). Utilizou-se o programa ICE para combinar as fotos e enviar para o sítio. A combinação não foi demorada, mesmo utilizando um computador com processador Core 2 Duo com Windows 7 e 2 GB de RAM (o melhor processador com valor acessível no momento é o i7 (3 gerações acima do processador que foi utilizado). Na Foto 1 tem-se um exemplo de visualização do resultado no sítio Photosynth.

\section{FOTO1: PRÉDIO DE CIÊNCIAS SOCIAIS APLICADAS DA UNIVERSIDADE} FEDERAL DO PARANÁ - 2 PAREDES

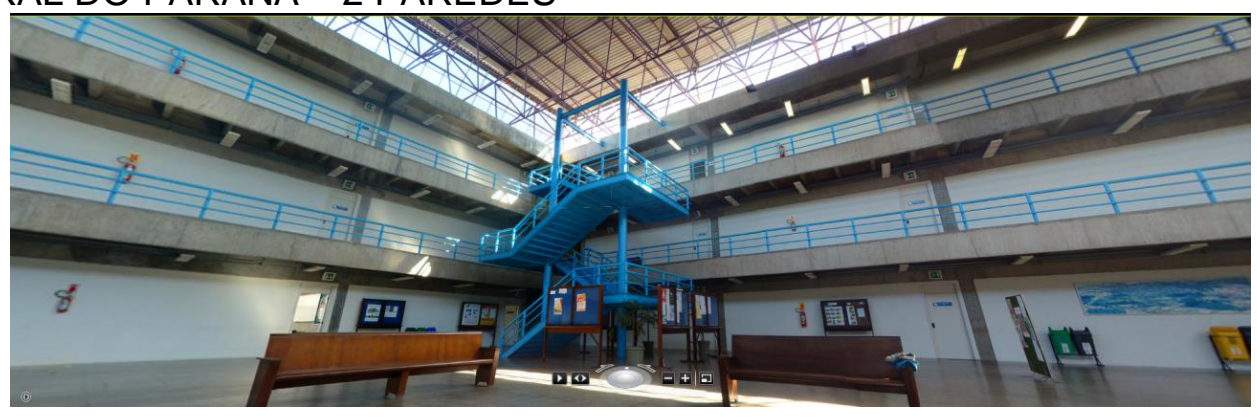

FONTE: Autora, Photosynth

Os banners foram utilizados como marcadores seguidos pelos murais e as escadas, pois se tratando de paredes que não possuem nenhuma diferenciação ou detalhe, o programa pode confundir a ordem das fotos no momento que as une automaticamente. 
FOTO 2: PRÉDIO DE CIÊNCIAS SOCIAIS APLICADAS DA UNIVERSIDADE FEDERAL DO PARANÁ - 3 PAREDES

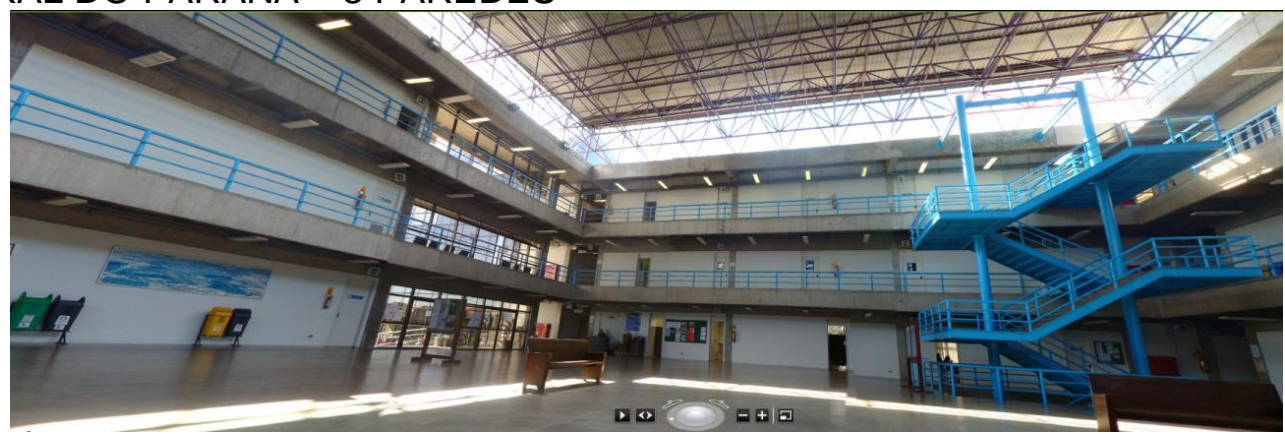

FONTE: Autora, Photosynth

Nas primeiras tentativas a foto final apresentou falha no centro do teto, problema que foi resolvido com o aprimoramento da técnica no ato de fotografar, sobrepondo em maiores graus a foto a ser tirada da anterior, o que consiste em fotografar a cada nova imagem um pedaço maior da imagem anterior. E passando de três (3) conjuntos de fotos na vertical das tentativas iniciais para quatro (4), aumentando o número total de fotos.

FOTO 3 - PRÉDIO DE CIÊNCIAS SOCIAIS APLICADAS DA UNIVERSIDADE FEDERAL DO PARANÁ - TETO

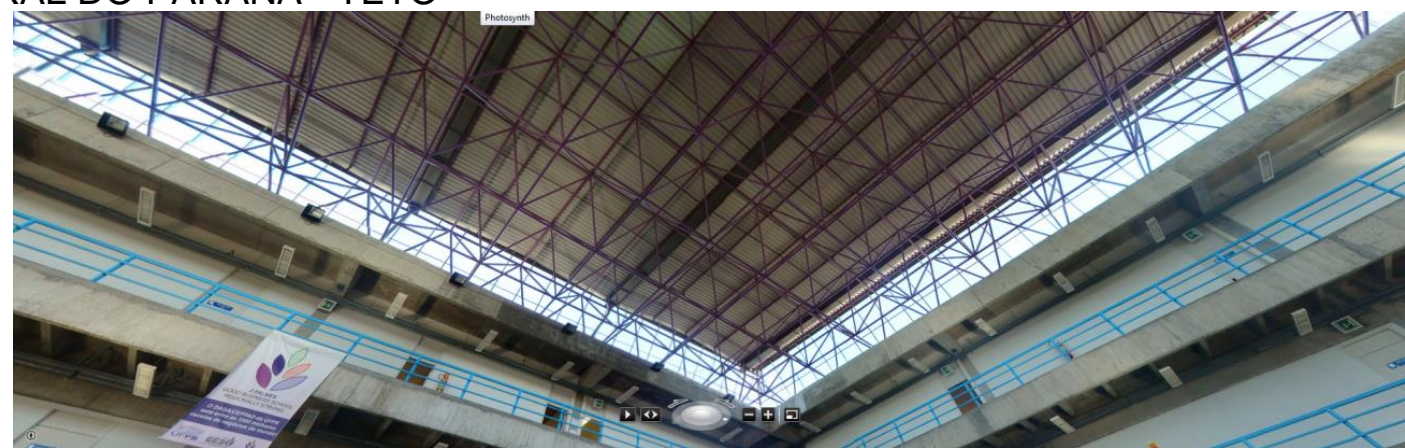

Fonte: Autora, Photosynth

O problema encontrado no centro do chão estava relacionado com o posicionamento do tripé. Tentou-se fotografar sem o auxílio do tripé, contudo por requerer repetição dos ângulos em cada foto em relação às anteriores, tanto na vertical quanto na horizontal não foi possível obter resultados satisfatórios. Outra tentativa ocorreu em fotografar os pés do tripé de modo a evitar o "buraco" no centro do chão e o resultado também não foi satisfatório, apresentando distorção (Foto 4). 
FOTO 4: PRÉDIO DE CIÊNCIAS SOCIAIS APLICADAS DA UNIVERSIDADE FEDERAL DO PARANÁ - CHÃO CENTRO

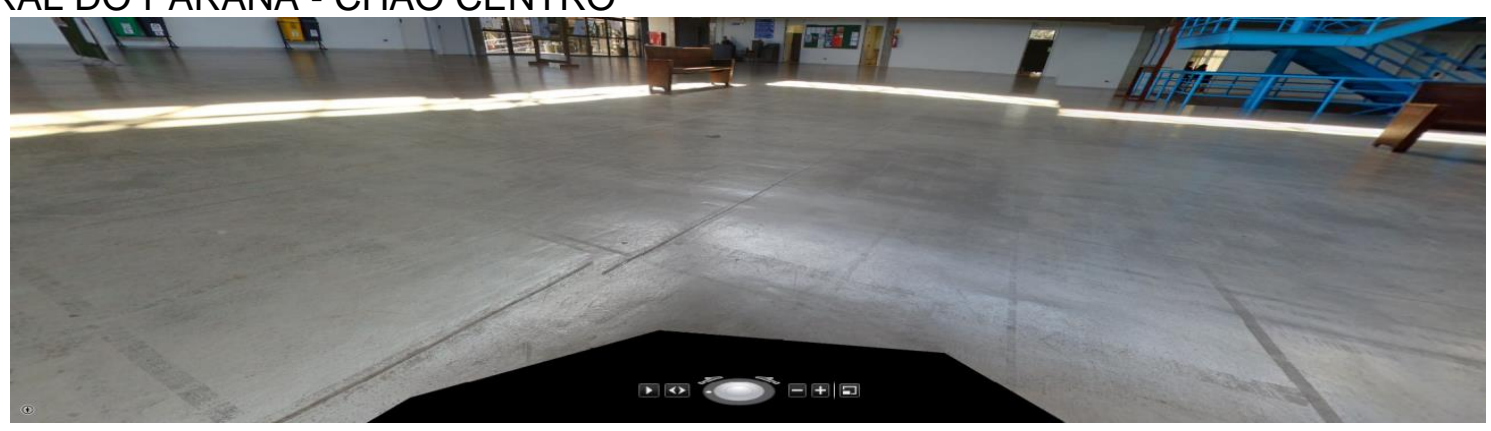

Fonte: Autora, Photosynth

O "buraco" concentra-se bem no centro do pátio, não permitindo um resultado cem por cento, no entanto não representa uma grande influência, visto que visualização geral e os detalhes importantes como bancos, escadas e entradas não é afetada.

FOTO 5: PRÉDIO DE CIÊNCIAS SOCIAIS APLICADAS DA UNIVERSIDADE FEDERAL DO PARANÁ - CHÃO

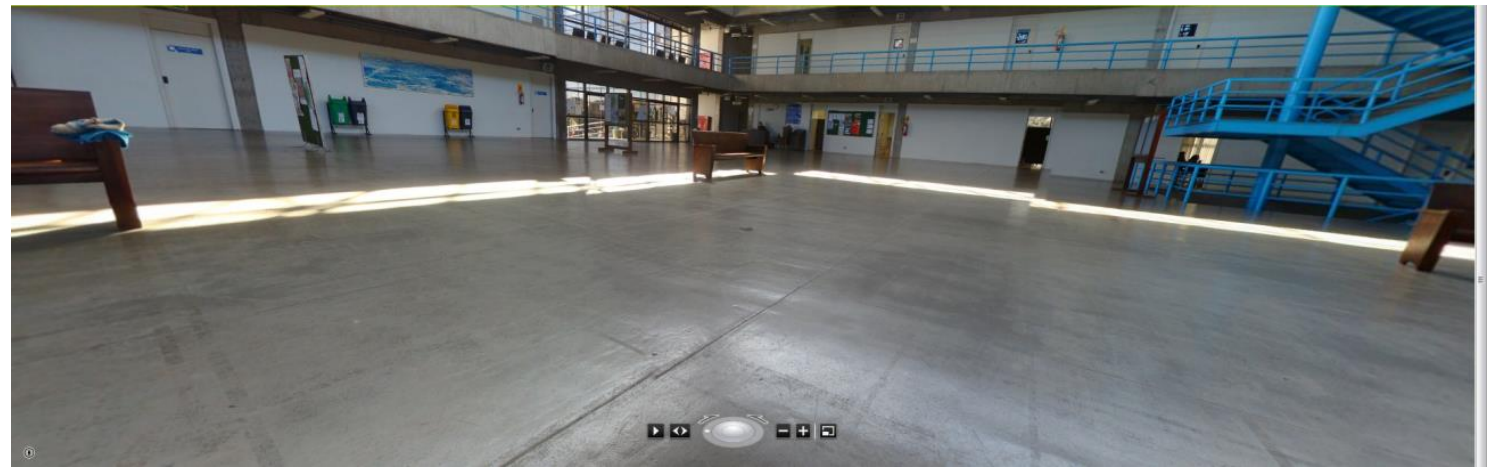

FONTE: Autora, Photosynth

Como dicas de uso para os professores, sugerimos: fotografar a parte interna e externa da escola, a sala de aula, sempre alinhados e interagindo com os assuntos pertinentes a matéria, por exemplo: biologia - parque, português - biblioteca, para que corra integração dos alunos com os temas e entre eles.

\section{Conclusão e Recomendações}

O uso de ferramentas tecnológicas simples, como a utilização da fotografia na educação é capaz de aumentar o interesse pelos estudos e consequentemente os níveis de aprendizado e conhecimento. 
Nesse artigo apresentou-se a evolução da fotografia ao longo dos tempos, desde a pintura (como recurso de guarda da imagem) até a acessível e simples fotografia digital. Detalhou-se o uso técnico e prático da ferramenta gratuita Photosynth, que permite a montagem da foto 360 graus esférica por junção das imagens. Essa ferramenta permite que os alunos se envolvam usando sua imaginação e criatividade, tornando o estudo agradável e motivador, possibilitando conhecer lugares nunca vistos e aprofundar 0 conhecimento sobre o que já era conhecido, através das fascinantes imagens.

Exemplificou-se ainda com uma aplicação de fotos 360 graus esféricas no pátio interno do Setor de Ciências Sociais Aplicadas da UFPR. Explorando os problemas e as dificuldades durante o experimento do projeto de extensão "Projeção e Visualização Científica dos 100 anos de Dados Históricos UFPR" em comemoração aos 100 ANOS DA UFPR.

Para estudos futuros recomenda-se pesquisa com alunos e docentes de escolas públicas sobre a utilização das fotos 360 graus esférica e a aceitação do mecanismo de ensino-aprendizagem e o nível de conhecimento em tecnologias.

\section{REFERÊNCIAS}

ARAUJO, J. B. e BUSNARDO A. Fotografia digital como prova no processo aspectos tecnológicos. In: Revista Âmbito Jurídico 2010. Disponível em: http://www.ambitojuridico.com.br/site/?n_link=revista_artigos_leitura\&artigo_id= 8787\&revista_caderno=21 Acessado em 26/09/2012.

BERNARDO, L. M., História da Luz e das Cores, Editora da Universidade do Porto, V.1, 2. Ed. 2007.

BUENO, E.L. Preservação de Documentos Fotográficos: Um Estudo Multicaso, 2010.

FARIA, M. L. L.; GERMANO J. E. Explorando Recursos de Multimídia e Ambientes de Ensino, ITA, 2003. 
FERNANDES, Hylio Lagana. Fotografia Como Mediadora Subversiva na Produção do Conhecimento. 2005. 245 f. Tese (Doutorado) - Departamento de Faculdade de Educação, Unicamp, Campinas, 2005.

FILHO, K. S. O; SARAIVA M. F. O. Astronomia \& Astrofísica, Editora Livraria da Física, 2.ed., São Paulo 2004.

GOMES, L.C.G. A História da Educação Através de Imagens Fotográficas e Outras fontes Complementares: Vários Espelhos de um Mesmo Objeto, v.5, número 2, 2003.

GUIMARÃES, C; SORG \& L. A lição digital. Revista Época (Ed. Junho/2011). Disponível em: <http://revistaepoca.globo.com/Revista/Epoca/0,,ERT24228515228-242285-3934,00.html>. Acesso em: 17 jun. 2011.

KOSSOY, B. Fotografia e História, 2.ed., Atelier Editorial, São Paulo, 2001.

OKA, C.; Roperto, A. Origens do Processo Fotográfico 2002. Disponível em : http://www.cotianet.com.br/photo/hist/menor.htm

RESENDE, H. Fotografe Uma Ideia! 2007-2012 Disponível em http://fotografeumaideia.com.br/site/index.php?option=com_content\&task=view \&id $=865 \&$ Itemid $=1$

SALLES, F. Fundamentos da fotografia. In: Revista Mnemocine 2008. Disponível em:http://www.mnemocine.art.br/index.php?option=com_content\&view=article\&i $d=108$ :histfoto\&catid=46:fotohistoria\&Itemid=68 Acessado em 22/09/2012.

SILVEIRA, L. S.; ALVES J. V. O Uso da Fotografia na Educação ambiental, Biblioteca UNESP, v. 3, número 2, 2008. 